PREFACE

\title{
Advances in applying climate prediction to agriculture
}

\author{
James W. Hansen ${ }^{1, *}$, Mannava V. K. Sivakumar ${ }^{2}$ \\ ${ }^{1}$ International Research Institute for Climate and Society, 121 Monell Bldg., Lamont-Doherty Earth Observatory, \\ PO Box 1000, 61 Route 9W, Palisades, New York 10964-8000, USA
}

${ }^{2}$ Agricultural Meteorology Division, World Meteorological Organization, 7bis avenue de la Paix, 1211 Geneva 2, Switzerland

Smallholder farmers are perhaps the segment of the population whose livelihoods are most susceptible to the impacts of climate variability. The majority of the world's poor and food-insecure depend on agriculture for livelihood and sustenance, and most of them live in regions that are characterized by marginal soils and climate, lack of access to irrigation and dependence on the uncertainty of rainfall. Climate fluctuations impact household subsistence production, farm incomes, local food prices and sometimes the economy of an entire region. Climatic extremes, such as droughts and floods, take a direct toll on lives, livelihoods, assets and infrastructure. For the risk-averse farmer, the inability to anticipate when climatic extremes will occur is a disincentive to adopt innovation. S/he must adopt conservative risk management strategies that serve as a buffer against climatic extremes, but that lead to inefficient resource use, reduced productivity and profitability, and accelerated resource degradation. Advance information in the form of seasonal climate forecasts potentially allows risk-averse farmers to relax conservative strategies and to capitalize more on average and good climatic seasons in a manner that can be reinvested in future livelihood opportunities that are available in the region. Timely implementation of individual responses and policy-level safety nets for coping with climate variability, informed by climate prediction, has the potential to reduce suffering and protect productive assets in the face of climate shocks.

The Climate Prediction and Agriculture (CLIMAG) program, initiated after the International Workshop on Climate Prediction and Agriculture (Sivakumar 2000) ${ }^{\mathbf{1}}$, was based on awareness of the adverse impact of climate variability on agriculture, as well as on the premise that advances in climate prediction at the sea-

${ }^{1}$ Sivakumar MVK (ed) (2000) Climate prediction and agriculture. Proc START/WMO Int Workshop, Geneva, Switzerland, 27-29 September 1999. International START Secretariat, Washington, DC sonal time scale contribute to adaptive management and resilience within agricultural systems, and hence to food and livelihood security. Much has been achieved during the ensuing years. The International Workshop on Climate Prediction and Agriculture: Advances and Challenges, held in Geneva, Switzerland, 11-13 May 2005, brought together 51 participants from 21 countries to review advances in the application of seasonal climate prediction in agriculture since the inaugural workshop in September 1999, and to identify challenges to be addressed in the next 5-10 years. The workshop's objectives were to:

- Synthesize the current status of seasonal climate predictions and their applications to smallholder agriculture

- Identify ways to foster greater use of seasonal climate forecasts for the benefit of smallholder agriculture and rural livelihoods in developing countries

- Develop an effective strategy for coordinating climate applications in a broader network of all users

- Promote regional research to enhance understanding of the complex interactions of climate with agricultural production and food security

Near-term priorities were identified for advancing the use of climate prediction for agricultural risk management:

- Increasing ownership and leadership by the agricultural development community

- Increasing engagement in national policy dialog

- Professional training and institutional capacity building

- Credible evaluation of production and livelihood benefits of climate applications

The workshop also highlighted opportunities to enhance integration-of seasonal prediction with other timescales of climate information, of forecast applications with agronomic and financial risk management, and of climate risk management with other development interventions. 
The articles in this CR SPECIAL $16^{2}$ represent a synthesis of key advances and remaining challenges in bringing climate prediction to bear on the needs of agriculture. In the opening article (p. 3-17, this issue), Sivakumar gives an overview of climate risks to agriculture and of approaches to seasonal forecasting, and provides examples of efforts to foster the use of advance information to manage climate risk. Sivakumar proposes that efforts in the near future should pay increased attention to: (1) improvement of forecast accuracy, (2) quantitative evidence of the utility of forecasts for agricultural risk management, (3) enhanced stakeholder participation, (4) communication with rural communities, (5) learning from adoption failures, (6) commodity trade and storage applications, and (7) the institutional and policy environment at the national level.

Two studies focus on prediction of climate fluctuations and their agricultural impacts. Doblas-Reyes et al. (p. 19-26, this issue) survey dynamic multi-model ensemble forecasts as a means of providing probabilistic forecast information, and highlight opportunities for downscaling in space, translating forecasts of climate variations into forecasts of economically important impacts and integrating seasonal prediction with information at shorter and longer time scales. They suggest that the climate forecast community is now capable of delivering an integrated system for probabilistic prediction of climate and its impacts on health, agriculture and hydrology, at a range of spatial scales and lead times. Hansen et al. (p. 27-41, this issue) then review progress in methodology for incorporating climate forecasts into probabilistic predictions of crop response. The methods reviewed offer several options, beyond the standard analog method, for incorporating dynamic climate models into applications that depend on probabilistic forecasts of crop yields, but have not been tested sufficiently.

The next 3 articles deal with economic aspects of climate forecast applications. Rubas et al. (p. 43-54, this issue) review 4 economic frameworks with increasing attention to stakeholder interactions-decision theory, general equilibrium modeling, game theory and mechanism design theory - that have potential to both contribute to and learn from climate applications. Rubas et al. suggest that economics has: (1) helped to understand how uncertain information can be incorporated into decisions, (2) served as a bridge between physical and social sciences and decision-makers, and (3) revealed the conditions under which climate information can have value. Impact assessment deals with providing evidence of the actual or potential benefit of an in-

\footnotetext{
2 Additional workshop papers are published in: Sivakumar MVK, Hansen JW (eds) (2006) Climate prediction and agriculture: advances and challenges. Springer, Heidelberg
}

tervention. Thornton's study (p. 55-65, this issue) deals with assessing a potential benefit before climate applications have been adopted. He highlights some of the challenges imposed by the nature of climate applications, and calls for using a range of quantitative and qualitative assessment methods. Msangi et al. (p. 67-79, this issue) discuss the application to climate risk management of methods for assessing the actual effect of agricultural development interventions, after they have been implemented and widely adopted. Although there are few examples where relevant climate forecast information has been disseminated and adequately supported long enough to allow these ex-post (i.e. after adoption) methods to be applied, understanding the methodology will enable advocates of climate risk management to provide evidence of uptake and benefit.

Many studies of the value of climate information for agriculture have employed qualitative methods that involve intensive interaction with farmers or other stakeholders. Roncoli (p. 81-99, this issue) reviews the contribution of ethnographic and participatory research. This research provides insights about climate perception that can inform communication efforts, and determinants of climate risk and its management that can inform other forms of support. Efforts are shifting from local farmer-centered approaches toward interactions among stakeholder at multiple scales.

The final 2 articles discuss institutional issues that influence the value of climate prediction to agriculture. Based on 3 case studies, Meinke et al. (p. 101-110, this issue) illustrate the important role that salience, credibility and legitimacy have in the uptake of climate information for risk management, and argue that systems analysis within a participatory process can foster these qualities in climate applications. Based on a case study in southern India, they warn that 'the creation of credibility...' through significant researcher-stakeholder engagement ' ...can bear within the seeds for its own destruction' by creating demand for climate services without a mechanism to meet the demand beyond the life of a pilot project. In the final article, Vogel \& O'Brien (p. 111-122, this issue) argue that inadequate attention to the complex social context has limited the effect of climate information on food security in southern Africa. They call for greater attention to the multiple stressors and risk responses that characterize the region, linkages between information needs and livelihood strategies, context within the existing network of institutions, and interactions with other development interventions.

Acknowledgements. We are grateful to Michel Jarraud, Secretary-General of the WMO, Roland Fuchs, Director of the International START Secretariat and Steve Zebiak, Director General of The International Research Institute for Climate and Society, for their support and encouragement, and to all the authors and reviewers who made this CR SPECIAL possible. 